\title{
Pengembangan Virtual Server dengan Proxmox VE 6.2 sebagai Cloud Computing berbasis Free/Open Source Software
}

\author{
Dessyana Kardha*1, Anton Respati Pamungkas ${ }^{2}$, Hendri Setiawan ${ }^{3}$ \\ 1,3Program Studi Sistem Komputer, STMIK AUB, Surakarta, Indonesia \\ ${ }^{2}$ Program Studi Sistem Informasi, STMIK AUB, Surakarta, Indonesia \\ e-mail: *1dessyanakardha@stmik-aub.ac.id,'anton18@stmik-aub.ac.id, \\ 3biging.yours@gmail.com
}

\begin{abstract}
Abstrak
Pada saat ini pengelolaan data dan layanan mahasiswa di STMIK AUB Surakarta belum dilaksanakan secara tersentral karena masih tersimpan di masing-masing unit pelaksana dan belum bisa saling terintegrasi satu sama lain serta server konten digital seperti: e-journal masih menggunakan web hosting dari luar, ini dikarenakan dalam segi tenaga ahli dan ketersediaan resource hardware perangkat server yang belum mampu dalam menunjang layanan kebutuhan mahasiswa yang telah tersedia sehingga bermuara pada belum optimalnya pemanfaatan infrastruktur virtual server di kalangan mahasiswa dan civitas akademika STMIK AUB Surakarta.

Tujuan penelitian ini untuk mengembangkan infrastruktur virtual server agar laya nan kebutuhan mahasiswa di STMIK AUB Surakarta seperti server konten digital e-learning, pengabdian alumni, pengelolaan data dan layanan mahasiswa menjadi tersentral, dapat terintegrasi dengan baik ke bagian-bagian unit pelaksana danfleksibel men dukung berbagai layanan kampus yang tersedia. Maka dilakukanlah penelitian yaitu membangun infrastruktur server cloud computing dengan Proxmox VE 6.2 dengan menggunakan metode System Infrastructure Development Life Cycle for Enterprise Computing Systems (SIDLC).

Hasil Penelitian dari topik ini adalah diimplementasikannya virtual server menggunakan Proxmox VE 6.2 yang berisikan beberapa sistem operasi yang berfungsi sebagai web server, file server, database server mendukung layanan e-learning dan pengabdian alumn $i$ sekaligus dapat fleksibel untuk mencakup seluruh civitas akademika. Kesimpulan dalam penelitian ini yaitu didapatkan infrastruktur virtual serveryang bekerja secara tersen tral dan saling terintegrasi dengan bagian unit pelaksana serta mendukung baik dalam perkuliahan elearning, pengolahandata dan layanan alumni ma hasiswa ma upun perangkat pendukung diluarnya.
\end{abstract}

Kata kunci-Virtual Server, Cloud Computing, Proxmox VE 6.2

Abstract

At this time, data management and student services at STMIK AUB Surakarta have not been implemented centrally because they are still stored in each implementing unit and cannot be integrated with each other and digital content servers such as: e-journals still use external web hosting. because in terms of experts and the availability of server hardware resources that have not been able to support the service needs of students that have been available so that it leads to not optimal utilization of virtual server infrastructure among students and the academic community of STMIK AUB Surakarta.

The purpose of this research is to develop a virtual server infrastructure so that the services needed by students at STMIK AUB Surakarta such as e-learning digital content

Received April 3, 2020; Revised April 13, 2020; Accepted June 17, 2020 
servers, alumni service, data management and student services are cen tralized, can be well integrated into the parts of the implementing unit and flexible support various services. available campuses. Then a research was carried out, namely building a cloud computing server infrastructure with Proxmox VE 6.2 using the System Infrastructure Development Life Cycle for Enterprise Computing Systems (SIDLC) method.

The research result of this topic is the implementation of a virtual server using Proxmox VE 6.2 which contains several operating systems that function as web servers, file servers, database servers that support e-learning services and alumni service as well as being flexible to cover the entire academic community. The conclusion in this study is that we get a virtual server infrastructure that works centrally and is mutually integrated with the implementing unit and supports both e-learning lectures, data processing and student alumni services as well as external supporting devices.

Keywords-Virtual Server, Cloud Computing, Proxmox VE 6.2

\section{PENDAHULUAN}

Virtualisasi server bermanfaat sebagai pertimbangan dalam perencanaan strategis pengembangan jaringan komputer di STMIK AUB Surakarta guna lebih fokus mendorong pengembangan teknologi yang terarah kepada penerapan di mitra industri dan masyarakat serta pengembangan capacity building STMIK AUB Surakarta, harapannya juga bagi Stakeholder STMIK AUB Surakarta lebih fokus pada tri dharma perguruan tinggi yaitu pendidikan, penelitian dan pengabdian masyarakat.

Pada saat ini infrastruktur virtual server yang telah tersedia di STMIK AUB Surakarta dimana dalam praktiknya belum dapat bekerja dengan optimal. Ditemukan bahwa sebagai media pendukung pelayanan kegiatan perkuliahan masih belum dimanfaatkan dengan baik. Terlihat pada pengelolaan data dan layanan mahasiswa belum dilaksanakan secara tersentral dan server konten digital seperti: e-journal masih menggunakan web hosting dari luar. Infrastruktur virtual server yang tersedia belum dapat terintegrasi dengan baik ke bagian-bagian unit pelaksana, sehingga bermuara pada belum optimalnya pemanfaatan virtual server di kalangan mahasiswa dan civitas akademika. Infrastruktur virtual server yang fleksibel juga sangat dibutuhkan agar dapat diandalkan oleh instansi. Fleksibilitas dalam konteks penelitian ini diukur berdasarkan pemanfaatan virtual server telah tersedia untuk mencakup seluruh area kampus agar mendukung berbagai layanan kampus yang tersedia.

Dari permasalahan tersebut, maka dibahas mengenai kendala atau permasalahan yang ada, lalu diangkat untuk dipecahkan dengan mengembangkan infrastruktur virtual server yang telah terse dia dengan menerapkannya tidak hanya sebagai file server atau file sharing directo ry untuk penyimpanan berkas. Namun penggunaan server tersebut akan juga menjadi infrastruktur layanan bagi kebutuhan mahasiswa di STMIK AUB Surakarta.

Untuk menyelesaikan permasalahan yang telah dijelaskan maka digunakan metode System Infrastructure Development Life Cycle for Enterprise Computing Systems (SIDLC) untuk memadukan konsep virtualisasi ke dalam bentuk hypervisor sehingga menjadi sebuah infrastuktur sistem berupa server fisik yang mampu menyediakan banyak server lain dan dapat menjalankan berbagai fungsi di dalamnya dan dengan dukungan jaringan komputer sebagai distribusi sistem agar dapat digunakan sebagai media pengelolaan data dan layanan bagi mahasiswa, sekaligus sebagai jawaban dari permasalahan yang dicoba untuk dipecahkan.

\section{METODE PENELITIAN}




\subsection{Teknik Pengumpulan Data}

Metode pengumpulan data adalah teknik atau cara yang dilakukan oleh peneliti untuk mengumpulkan data. Metode pengumpulan data yang digunakan penulis antara lain:

a. Teknik Observasi

Teknik pengumpulan data yang dilakukan melalui peninjauan langsung ke wilayah STMIK AUB Surakarta yang akan diteliti. Yakni pengelolaan data untuk mahasiswa dan layanan bagi alumni di bagian unit pelaksana pihak kampus dan penggunaan server konten digital yang sudah tersedia.

\section{b. Teknik Wawancara}

Teknik pengumpulan data dengan wawancara dapat dilakukan secara terstruktur maupun tidak terstruktur dan dapat dilakukan melalui tahap. Maka penulis melakukan wawancara dengan Agung Nugroho selaku ketua laboratorium di STMIK AUB Surakarta dengan pembahasan topik mengenai banyak pengguna (user), model konektivitas jaringan, dan pemetaan jaringan untuk kebutuhan sistem server yang akan diterapkan pada jaringan internet untuk lingkup wilayah STMIK AUB Surakarta.

\section{c. Studi Literatur}

Penulis mencari, membaca dan mempelajari referensi berupa jurnal dan buku-buku yang berhubungan dengan penelitian yang dilakukan tentang Virtual Server menggunakan Proxmox VE sebagai cloud computing dengan basis free open source software beserta beberapa informasi tambahan mengenai sistem operasi yang ditanam didalamnya.

\subsection{Tahap - Tahap Penelitian}

Penulis mencari, membaca dan mempelajari referensi berupa jurnal dan buku-buku yang berhubungan dengan penelitian yang dilakukan tentang Virtual Server menggunakan Proxmox VE sebagai cloud computing dengan basis free open source software beserta beberapa informasi tambahan mengenai sistem operasi yang ditanam didalamnya:

\section{a. Analysist}

Pada tahapan ini dilakukan dengan menganalisa data mengenai infrastruktur virtual server sebagai media pendukung pelayanan mahasiswa dan civitas akademika harus bisa dimanfaatkan dan terintegrasi dengan optimal. Penggunaan server konten digital yang fleksibel juga sangat dibutuhkan agar dapat diandalkan oleh kampus.

\section{b. Design}

Melalui pendekatan metode SIDLC tahapan desain dilakukan dengan menyesuaikan beberapa faktor lingkungan sistem, lokasi pengguna, perangkat, aplikasi, dan aktivitas yang dapat dilakukan pengguna dengan infrastuktur server yang dibangun.

\section{c. Testing}

Pengujian dilakukan dengan membuat prototype menggunakan Virtual Box. Aplikasi yang digunakan untuk pengujian ini adalah nslookup dan ping. Termasuk pula pengujian utama layanan virtual machine (VM).

\section{d. Implementation}

Pada tahapan implementasi dilakukan dengan mengkonfigurasi virtual server dengan beberapa sistem operasi. Server dan controller dikonfigurasi keduanya dan dihubungkan melalui TCP/IP. Konfigurasi yang ditanamkan pada jaringan dengan menggunakan pengalamatan IP statis agar akses dan layanan tidak berubah ubah.

\section{e. Maintenance}

Beberapa permasalahan yang nantinya ditemukan seperti IP conflict, kesalahan pada firewall dan interface configuration bahkan pengkabelan. Atau dari dalam sistem sendiri seperti switching port, server shutdown, slowness, overloaded server, misconfigured DNS. Se muanya didokumentasi dan dilakukan troubleshooting atau dilakukan recovery procedure. 


\section{HASIL DAN PEMBAHASAN}

\subsection{Unit Penelitian}

Penelitian dilakukan di STMIK AUB Surakarta Jl. Walanda Maramis No.29, Nusukan, Kec. Banjarsari, Kota Surakarta, Jawa Tengah.

\subsection{Analisa Perangkat Keras}

Tabel 1. Kebutuhan Perangkat Keras

\begin{tabular}{|c|l|l|l|}
\hline No. & Device Name & Specification & Jumlah \\
\hline 1 & Processor & $\begin{array}{l}\text { CPU Dual Core Intel } \\
\text { Processor }\end{array}$ & 1 Pcs \\
\hline 2 & Memory & 6 GB of DDR3 RAM & 2 Pcs \\
\hline 3 & Harddisk & 160 GB, SATA & 2 Pcs \\
\hline 4 & Network Card & 100 Mbps Fast Ethernet & 1 Pcs \\
\hline 5 & UTP Cable & Min. Cat5E & 1 M \\
\hline 6 & Modem Router & $\begin{array}{l}\text { Huawei4G Router B310 } \\
\text { with LTE CAT4 up to } \\
150 M b p s\end{array}$ & 1 Unit \\
\hline 7 & Kartu SIM & Perdana Internet & 1 Pcs \\
\hline
\end{tabular}

\subsection{Analisa Perangkat Lunak}

Tabel 2. Kebutuhan Perangkat Lunak

\begin{tabular}{|c|l|l|l|}
\hline No & Nama Perangkat & Spe sifikasi & Jumlah \\
\hline 1 & Proxmox VE 6.2 & $\begin{array}{l}\text { IaaS (Server Cloud) dan } \\
\text { Engine Virtualization }\end{array}$ & 1 Pcs \\
\hline 2 & TurnKey Linux & $\begin{array}{l}\text { Virtual Appliance, SaaS, } \\
\text { Open VZ Container, KVM }\end{array}$ & 2 Pcs \\
\hline 3 & $\begin{array}{l}\text { All Browser Java } \\
\text { Enabled }\end{array}$ & $\begin{array}{l}\text { Remote VM, OpenVZ dan } \\
\text { KVM }\end{array}$ & 1 Pcs \\
\hline
\end{tabular}

\subsection{Cara Kerja Sistem}

Secara umum, cara kerja sistem Proxmox VE telah dijelaskan pada diagram block. Proxmox VE dijalankan dengan sistem operasi yang berjalan yang berupa virtual machine dan container yang di kontrol melalui konsol terintegrasi didalamnya. Antar sistem operasi terhubung dalam jaringan ter-bridge dengan kontrol keamanan yang dibatasi menggunakan firewall berlapis. Yakni melalui datacenter, node, dan dari LXC container ataupun KVM Virtual Machine, seperti ditunjukkan di Gambar 1. 


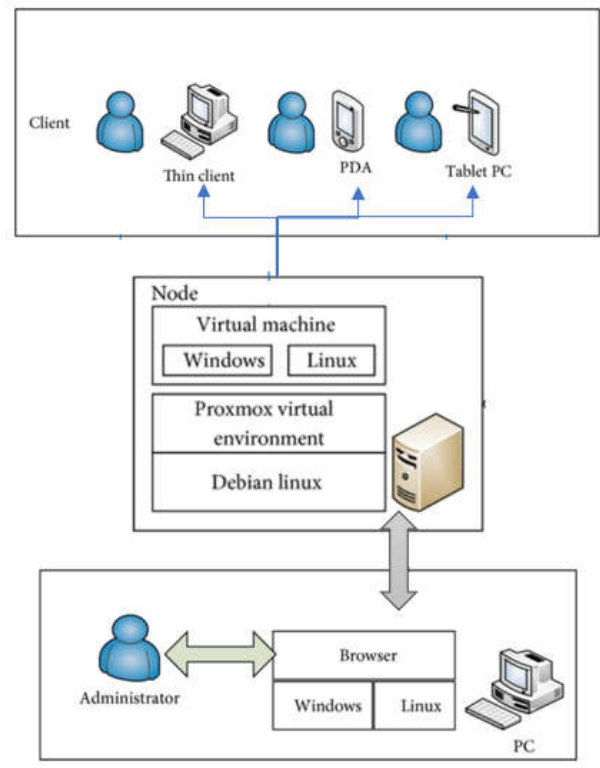

Gambar 1. Visualisasi kerja sistem

\subsection{Desain Sistem yang sedang Berjalan}

Saat ini, STMIK AUB Surakarta belum mengimplementasikan komputer server. STMIK AUB Surakarta masih menggunakan satu jasa Hosting VPS untuk dijadikan sebagai server website, seperti yang dijelaskan pada Gambar 2. Adapun konsep topologi yang sudah berjalan pada STMIK AUB Surakrta seperti di bawah ini:

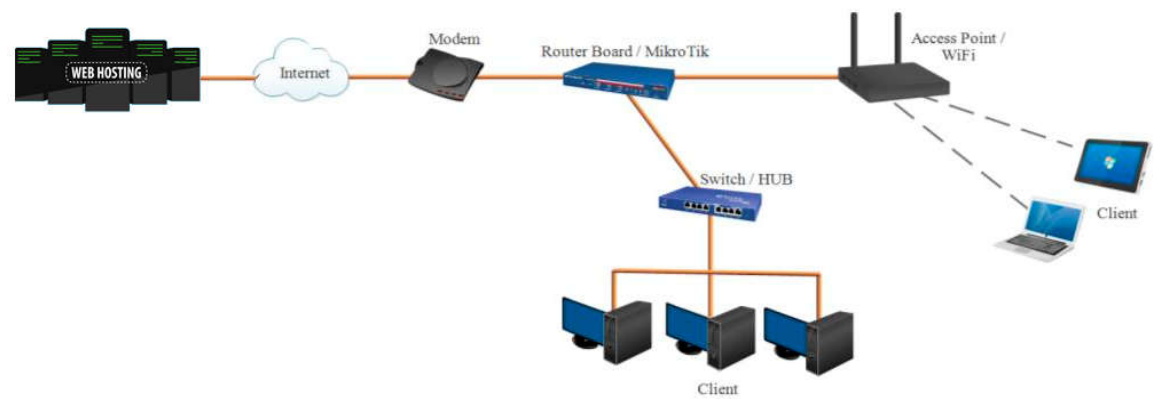

Gambar 2. Topologi Jaringan yang Berjalan

3.6 Desain Sistem yang Dibangun

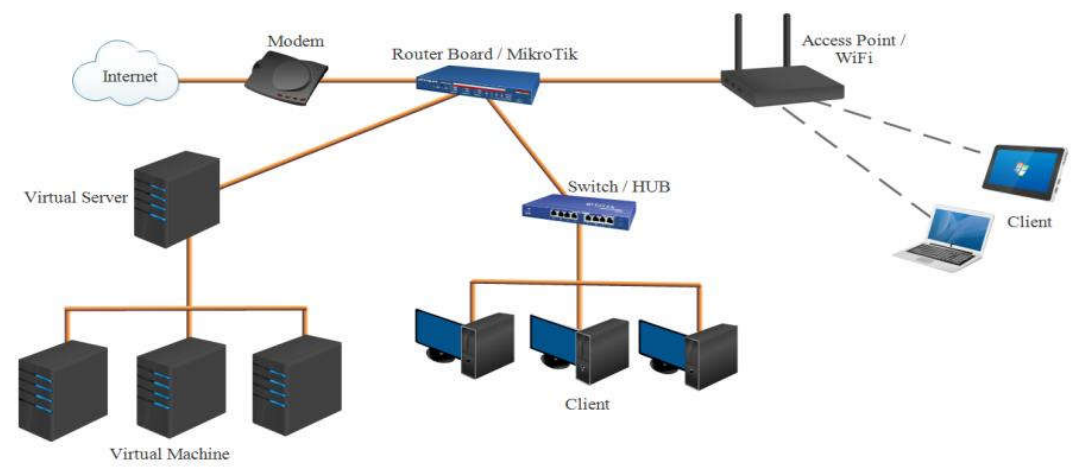

Gambar 3. Topologi Jaringan yang Dibangun

Berdasarkan topologi diatas, dapat dilihat terdapat penambahan 1 server fisik dan 3 mesin server virtual. Ketiga mesin server virtual yang berada dalam server fisik tersebut mempunyai

GO INFOTECH: JURNAL ILMIAH STMIK AUB Vol. 26, No. 1, Juni 2020: 85 -95 
tugas dan fungsi berbeda. Web Server dalam topologi tersebut berfungsi untuk menyediakan akses web STMIK AUB Surakarta. Hypervisor menggunakan sistem operasi Proxmox Virtual Environment 6.2 dan menggunakan Debian Linux sebagai media Virtual Machine.

\subsection{Pengujian Perangkat}

Pengujian alat dilakukan dengan menjalankan perangkat server dan melakukan pengaksesan baik dengan melakukan remote, menguji konektifitas melalui port tertentu dan menjalankan virtual machine dalam waktu bersamaan.

a. Akses ke Proxmox VE melalui port 8006

Proxmox dikontrol melalui konsol terintregrasi dalam bentuk laman web. Akses web console dengan mode Graphical User Interface (GUI) yang hanya dapat dibuka melalui port 8006, sepertipada Gambar 4.

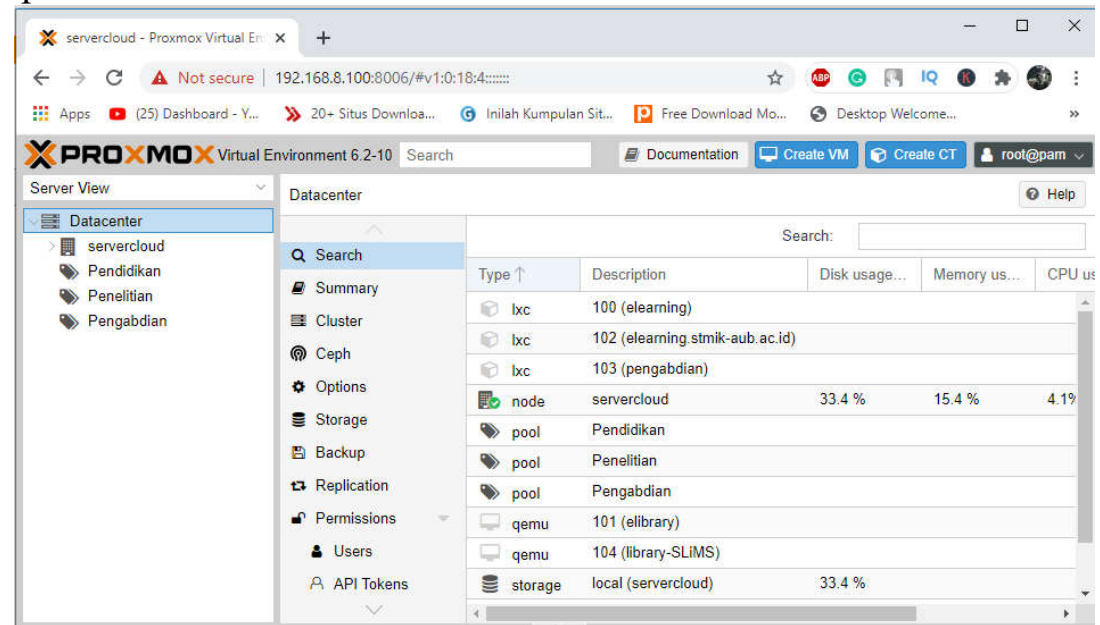

Gambar 4. Web Console Proxmox VE melalui port 8006

b. Akses ke Proxmox VE melalui Secure Shell (SSH)

Selain menggunakan mode GUI, pengaksesan hypervisor dapat dilakukan melalui mode Command Line Interface (CLI) Sepertipada gambar 5. Penggunaan metode CLI memungkinkan mengatur konfigurasi yang tidak dapat dirubah melalui konsol web.

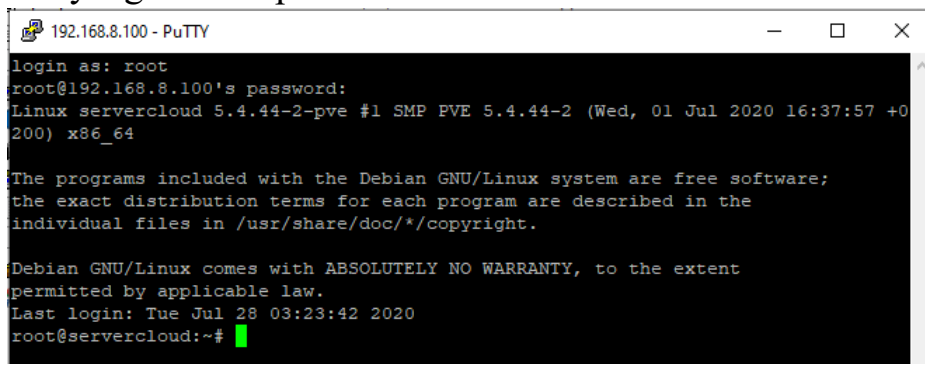

Gambar 5. Akses CLI menggunakan aplikasi Putty

c. Akses ke VM menggunakan Console Qemu

Pengujian mesin virtual Debian 10 menggunakan Console Qemu pada klien seperti pada Gambar 6. menunjukan bahwa sistem mampu berjalan dengan baik. 


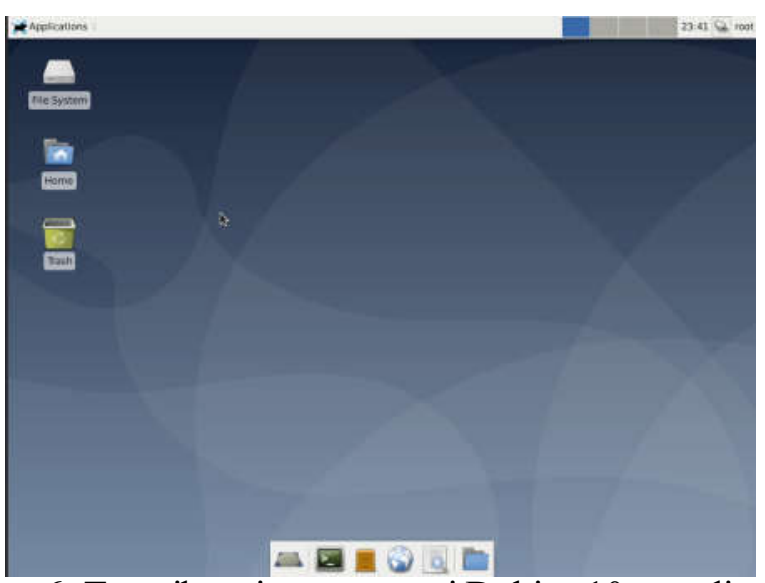

Gambar 6. Tampilan sistem operasi Debian 10 saat di remote

d. Akses ke Linux Container (LXC)

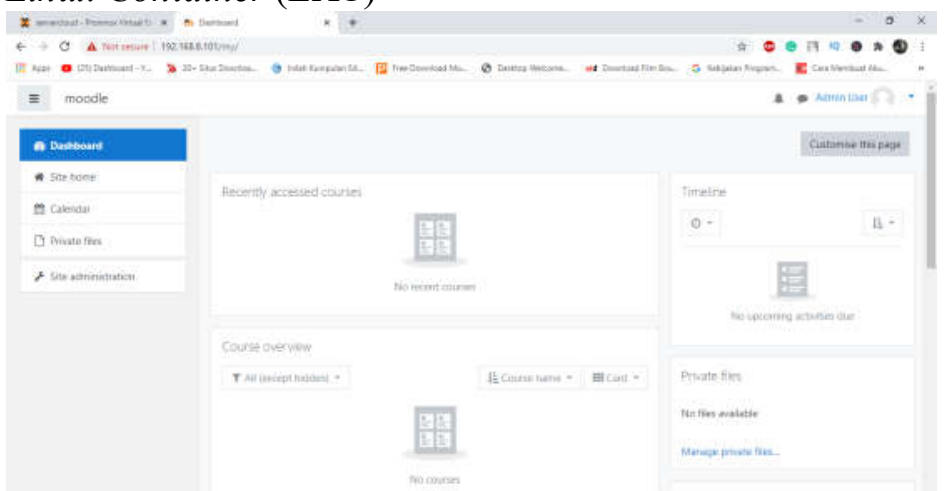

Gambar 7. Pengujian Moodle Elearning

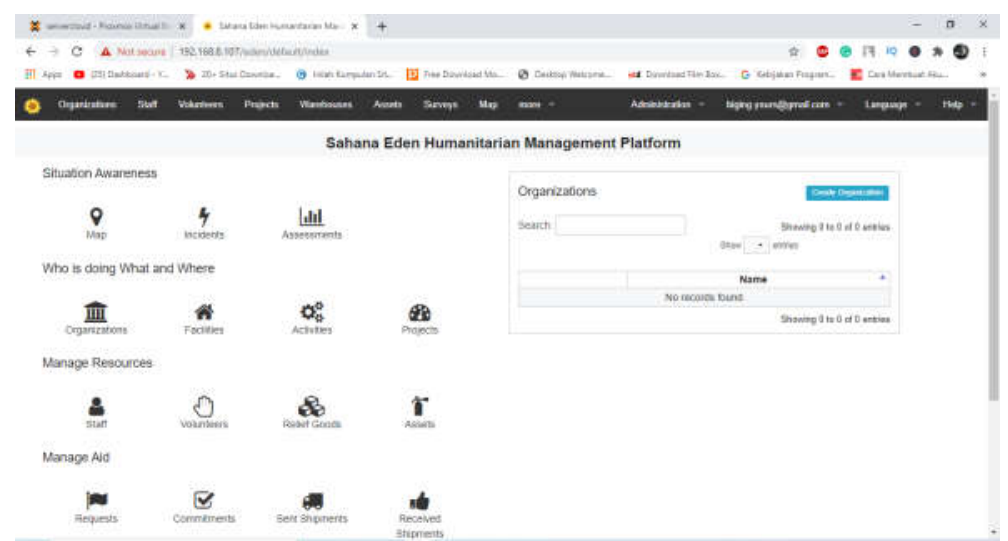

Gambar 8. Pengujian Sahan Eden Pengabdian Alumni

\subsection{Pengujian Perangkat Lunak}

Mampu menjalankan tiga sistem operasi secara bersamaan yakni yang ditampilkan pada Tabel 3 berikut.

Tabel 3. Informasi Sistem Operasi yang terpasang

\begin{tabular}{|c|l|l|l|}
\hline No & Nama Sistem Operasi & Je nis Virtualis asi (KVM/CT) & Spe sifikasi \\
\hline 1 & Debian Linux & CT & $\begin{array}{l}\text { Web Server Moodle, } \\
\text { Memory 256 MB, } 1\end{array}$ \\
\hline 2 & Debian Linux & CT & $\begin{array}{l}\text { Web Server Sahana Eden, } \\
\text { Memory }\end{array}$ \\
\hline
\end{tabular}

GO INFOTECH: JURNAL ILMIAH STMIKAUB Vol. 26, No. 1, Juni 2020: 85 -95 


\begin{tabular}{|l|l|l|l|}
\hline 3 & Debian Linux & KVM & $\begin{array}{l}\text { Web Server SLiMS, } \\
\text { Memory }\end{array}$ \\
\hline
\end{tabular}

\subsection{Pengujian Performa Perangkat Server}

Dari pengamatan memori yang digunakan untuk menjalankan beberapa virtual machine sekaligus. Seperti yang ditunjukan pada Tabel 4 dengan harga 0 untuk container / virtual machine yang mati, dan harga 1 untuk container / virtual machine yang berjalan. Pengujian dengan menggunakan satu klien laptop.

Tabel 4. Pengamatan performansi hypervisor

\begin{tabular}{|c|c|c|c|c|}
\hline \multicolumn{3}{|c|}{ CT / VM ID } & $\%$ & $\%$ \\
\hline VM 103 & CT 101 & CT 100 & Processor & Memory \\
\hline 0 & 0 & 0 & 1.62 & 20.37 \\
\hline$\overline{0}$ & $\overline{0}$ & 1 & 2.10 & 22.47 \\
\hline$\overline{0}$ & 1 & 0 & 1.31 & 20.68 \\
\hline$\overline{0}$ & 1 & 1 & 1.46 & 22.65 \\
\hline 1 & 0 & 0 & 9.04 & 47.78 \\
\hline 1 & 0 & 1 & 4.46 & 50.05 \\
\hline 1 & 1 & 0 & 15.77 & 48.10 \\
\hline 1 & 1 & 1 & 13.95 & 50.34 \\
\hline
\end{tabular}

\subsection{Pembahasan}

Setelah seluruh perangkat terpasang dan teruji bahwa sistem berjalan dengan normal, selanjutnya adalah menentukan skenario penggunaan sistem dalam hypervisor.

a. Skenario Pengguna untuk kelompok server Pendidikan

Pada kelompok server Pendidikan, yang dapat menggunakan adalah user root, dan tipe pengguna dosen. Dosen harus login terlebih dahulu dengan username dan password menggunakan realm Proxmox VE Authentification. Lalu menjalankan sistem operasi yang dipakai.

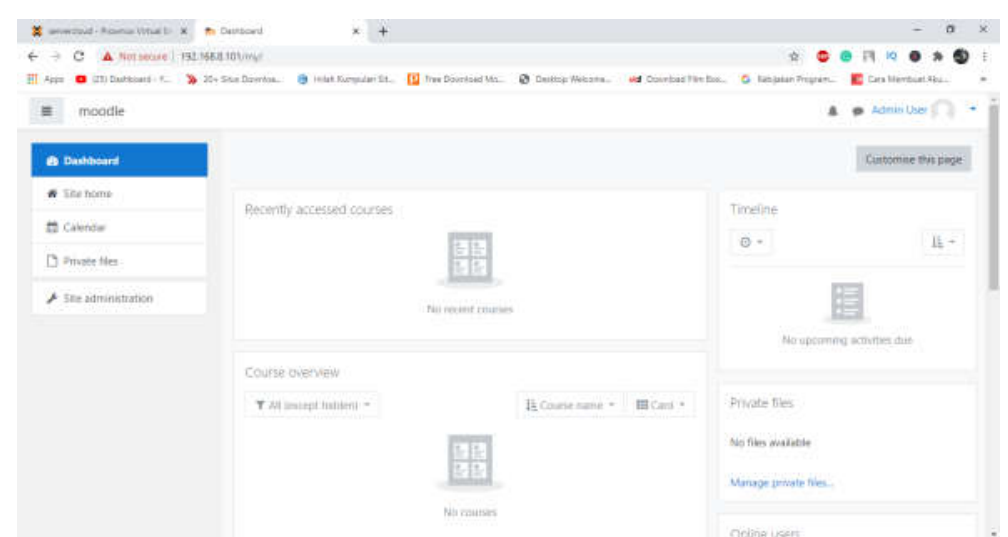

Gambar 9. Skenario layanan moodle e-learning

b. Skenario Pengguna untuk kelompok server Pengabdian

Pada kelompok server Pengabdian, yang dapat menggunakan adalah semua pengguna civitas akademika STMIK AUB Surakarta. Pengguna tersebut harus login terlebih dahulu dengan username dan password menggunakan realm Proxmox VE Authentification. Lalu menjalankan menu yang disediakan. 


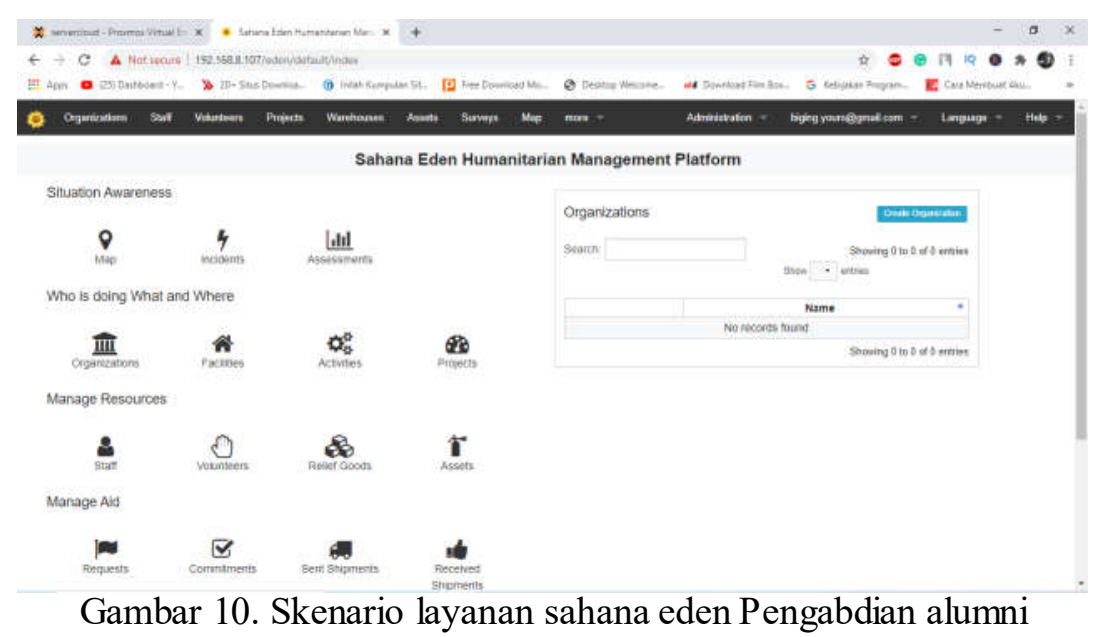

c. Skenario Pengguna untuk kelompok server Penelitian

Pada kelompok server Penelitian, yang dapat menggunakan adalah semua pengguna civitas akademika STMIK AUB Surakarta. Pengguna tersebut harus login terlebih dahulu dengan username dan password menggunakan realm Proxmox VE Authentification. Lalu menjalankan sistem operasi yang dipakai.

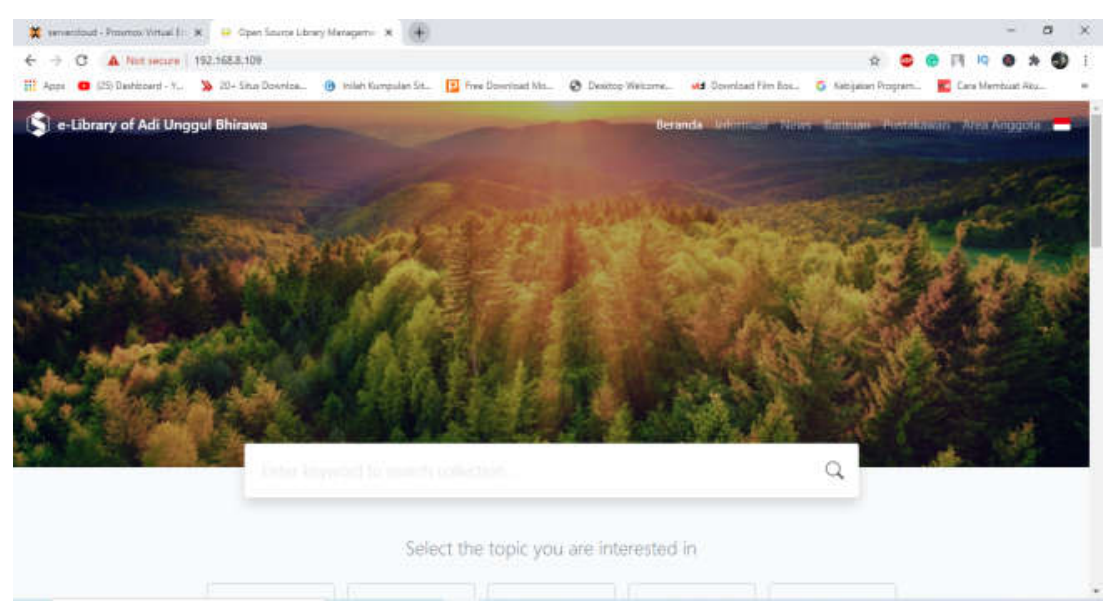

Gambar 11. Skenario layanan SLiMS e-library

\section{KESIMPULAN}

Dari penelitian tersebut maka dapat diselesaikanlah permasalahan mengenai membangun infrastruktur server yang mampu menjadi sentral bagi banyak aplikasi yang digunakan STMIK AUB Surakarta baik dalam perkuliahan e-learning, pengolahan data dan layanan alumni mahasiswa maupun perangkat pendukung diluarnya.

\section{SARAN}

Untuk penelitian yang lebih lanjut dapat dibangun dengan topologi yang lebih kompleks misalnya jumlah server yang lebih banyak dan berada pada jaringan yang berbeda. Penggunaan SSO atau Single Sign On agar dengan satu akses mampu mengakses seluruh fitur server.

\section{DAFTAR PUSTAKA}

[1] Adiwibowo, Wishnumurti. 2013. Kernel-Based Virtual Machine Untuk Virtualisasi Database Sebagai Solusi Kebutuhan Perangkat Keras Studi Kasus Implementasi Sistem 
Informasi Klinik Kecantikan. Jurnal Transformatika. Volume 10, No. 2 Januari 2013. Semarang: Universitas Semarang.

[2] Afriandi, Arief. 2012. Perancangan, Implementasi, dan Analisisi Kinerja Virtualisasi Server Menggunakan Proxmox, VMWare ESX, dan OpenStack. Jurnal Informasi Volume 5 No. 2 Desember 2012.Yogyakarta : Universitas Gajah Mada.

[3] Agung, R. 2013. Pengertian dan Jenis Routing. mikrotikindo.blogspot.com. diakses pada tanggal 7 Juni 2020.

[4] Ahmed, Wasim. Mastering Proxmox. Edisi Kedua. United Kingdom: Packt Publising. 2014: 11-13.

[5] Arianto, 2017, Perbandingan Full Virtualization dan Paravirtualization untuk Mendukung Efisensi Energi, Skripsi, Teknik Komputer Universitas Indonesia.

[6] Dillon, Tharam. Cloud Computing: Issues and Challenges. Edisi Pertama. Australia: IEEE. 2010: 5-7.

[7] Fadjirin, Akbar, Jahnsen Gultom. 2013. Cloud Computing Server Menggunakan Proxmox Pada CV. Cipta Solusi Sejahtera. Jurnal Transformatika. Volume 11, No. 4 Januari 2014. Palembang: STMIK PalComTech.

[8] Firmansyah, Yudha Christianto. 2019. Analisis Teknologi Virtual Mesin Proxmox dalam Rangka Persiapan Infrastruktur Server. Jurnal INFORMA Politeknik Indonusa Surakarta Vol. 5 Nomor 3 Tahun 2019.

[9] Harijanto, Budi. 2015. Desain dan Analisis Kinerja Virtualisasi Server menggunakan Proxmox Virtual Environment. Jurnal Simantec Vol. 5, No.1 Desember 2015.

[10] Jiang, Min. Jong, Chu J. Poppell, Paul. Budhathoky, Keshab. Hull, Ryan. System Infrastructure Development Life Cycle for Enterprise Computing Systems. Edisi Pertama. China: IEEE. 2009: 4-6.

[11] Julianti, M. Ramaddan. 2019. Perancangan Server Cloud Computing Model Infrastructure As A Service Berbasis Proxmox pada PT Fortuna Mediatama. Academic Journal of Computer Science Research Vol. 1 No. 1, July 2019.

[12] Kovari, A. Dukan, P. KVM \& OpenVZ virtualization based IaaS Open Source Cloud Virtualization Platforms: OpenNode, Proxmox VE. Edisi Pertama. Serbia: IEEE. 2012: 710.

[13] Nuhajat. 2014. Membangun Cloud Computing berbasis Free/Open Source Software (F/OSS) pada STMIK Widya Cipta Dharma. Academic Journal of Computer Science Research Vol. 1 No. 1, July 2019. Samarinda: STMIK Widya Cipta Dharma.

[14] O'brien. Virtualisasi Server dengan Proxmox untuk Pengoptimalisasian Penggunaan Resource Server pada Upt Teknologi dan Komunikasi Pendidikan http://ibrary.binus.ac.id/eColls/eThesisdoc/Bab2HTML/

2013101251 KABab2001/page9.html diakses tanggal 17 Maret 2020.

[15] Perdana, Noki Putra. Pembangunan Jaringan Local Area Network (Lan) PT. Niaga Swadaya Yogyakarta. http://ijns.org/journal/index.php/seruni/article/ view/607 diakses pada 15 April 2020.

[16] Prasandy, Teguh. Wishnumurti. 2015. Virtualisasi Server Sederhana Menggunakan Proxmox. Jurnal Transformatika, Volume 12 No.2 Januari 2015.

[17] Prawedha, Dhantel Rhesa. 2018. Rancang Bangun Hypervisor Menggunakan Proxmox VE 5.0 Sebagai Virtual Server Infrastructure di STMIK AUB Surakarta. Jurnal P ublika si Komputer 2018 Vol 2. No.1. Surakarta: STMIK AUB Surakarta.

[18] Rafiudin, R. Panduan Membangun Jaringan Komputer Untuk Pemula. cet.2. Jakarta: P T Elex Media Komputindo. 2003: 10-14.

[19] Suhatman, Rachmat. 2016. Analisa Performansi Server Cloud Berbasis Proxmox VE untuk Multi Server dan Multi Platform pada Praktikum Administrasi Jaringan Komputer. Jurnal Komputer Terapan Vol 2. No.1 Mei 2016. 
[20] Suryono, Tito. 2012. Pembuatan Prototype Virtual Server Menggunakan Proxmox VE Untuk Optimalisasi Resource Hardware di NOC FKIP UNS. Indonesian Journal on Networking and Security. Volume 1 Nomor 1 - November 2012. Teknik Informatika.

[21] Syamsudin, Ricky Chandra. 2014. Perancangan Servercloud Computing Menggunakan Proxmox. Jurnal SATIN - Sains dan Teknologi Informasi, Vol. 3, No. 2, Desember 2014. Teknik Elektro dan Komputer.

[22] Towidjojo, R. Konsep dan Implementasi Routing dengan Router Mikrotik. Edisi Pertama. Jakarta: Jasakom. 2013: 40-43.

[23] Yuhefizar. 2003. Tutorial Komputer dan Jaringan. http:/ilmukomputer.com diakses pada 27 Juni 2020. 